\section{Response to 'Dual training in general internal medicine and rheumatology: the Irish context' by Dr Sheane}

We would like to thank Dr Sheane for his interest in our paper ${ }^{1}$ and for his comments providing further insight into the Irish situation. ${ }^{2}$ As he highlights Ireland is one of the European League Against Rheumatism (EULAR) member countries with the longest training in general internal medicine (GIM) followed by a relatively short training in rheumatology. There is a general consensus that rheumatology is a specialty closely related to GIM, as all countries but one includes mandatory training. However, the training can take place at several timepoints (before or during the training programme) and carries a different weight and length in each country. Many of these differences seem to result from local traditions and idiosyncrasies but not from a conscious decision-making process of societal needs.

In fact, this project is a first step, aimed at defining the issue of European heterogeneity in training in rheumatology and its magnitude. A further second step will analyse the training experience in the different countries by gathering information and opinions from trainees and young rheumatologists. After we are aware of the current situation, relevant discussions should take place at a European level in order to promote an increase in the European harmonisation and the quality of training. It is essential that rheumatologists from the different countries engage in these efforts, leading discussions with relevant stakeholders. Otherwise change and improvement will prove impossible. We hope that these data collected at a European level can support local discussions in each of the countries in an attempt towards harmonisation of training across Europe.
Francisca Sivera, ${ }^{1}$ Sofia Ramiro, ${ }^{2,3}$ Johannes W Bijlsma ${ }^{3,4}$

${ }^{1}$ Rheumatology Unit, Hospital Elda, Elda, Spain

${ }^{2}$ Hospital Garcia de Orta, Almada, Portugal

${ }^{3}$ Amsterdam Rheumatology Center, Amsterdam, The Netherlands

${ }^{4}$ University Medical Center Utrecht, Utrecht, The Netherlands

Correspondence to Dr Francisca Sivera, Rheumatology Unit, Hospital Elda, Elda 03600, Spain; fransimas@yahoo.es

Contributors FS drafted the reply and all authors revised and approved the final draft.

Competing interests None declared.

Provenance and peer review Commissioned; internally peer reviewed.

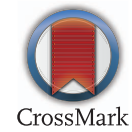

To cite Sivera F, Ramiro S, Bijlsma JW. Ann Rheum Dis 2015;74:e56.

Received 3 May 2015

Accepted 10 May 2015

Published Online First 29 May 2015

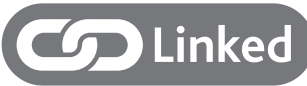

http://dx.doi.org/10.1136/annrheumdis-2015-207782

Ann Rheum Dis 2015;74:e56. doi:10.1136/annrheumdis-2015-207813

\section{REFERENCES}

1 Sivera F, Ramiro S, Cikes N, et al. Differences and similarities in rheumatology specialty training programmes across European countries. Ann Rheum Dis 2015;74: $1183-7$.

2 Sheane BJ. Dual training in general internal medicine and rheumatology: the Irish context. Ann Rheum Dis 2015;74:e55. 